\title{
Critical Illness Neuromyopathy Complicating Cardiac Surgery
}

\author{
Wan Ki Baek ${ }^{1}$, Young Sam Kim ${ }^{1}$, Joung Taek Kim ${ }^{1}$, and Byoung-Nam Yoon ${ }^{2}$ \\ ${ }^{1}$ Department of Thoracic and Cardiovascular Surgery, ${ }^{2}$ Department of Neurology, Inha University Hospital, Incheon, Korea
}

Critical illness neuromyopathy (CINM) is a sporadically reported disease in the setting of an intensive care unit developing in the process of managing a critical illness. The disease primarily affects the motor and sensory axons and results in severe limb weakness rendering ventilator weaning extremely difficult. We report a case of CINM after cardiac valve surgery. Quadriplegia developed after the operation and resolved slowly over the following 2 months. The patient was discharged home free of neurologic symptoms.

Key Words: critical illness; electromyography; nerve conduction; neuromuscular diseases; rehabilitation; thoracic surgery

Critical illness neuromyopathy (CINM) is a disease entity characterized by flaccid and usually symmetrical weakness resulting from an axonal degeneration of peripheral nerves developing on the way of managing critical illness in the setting of intensive care unit (ICU) [1]. CINM after cardiac surgery is widely unrecognized. We herewith describe a case with a review of the literature.

\section{CASE REPORT}

A 50-year-old female was referred for open heart surgery under the diagnosis of mitral stenosis and aortic regurgitation combined with atrial fibrillation. She had a history of percutaneous mitral valvuloplasty for mitral stenosis 11 years earlier. Her dyspnea worsened over the last 3 years and she was in New York Heart Association (NYHA) functional class III at presentation. She was in good physical shape, weighing $66 \mathrm{~kg}$, and had no neuromuscular abnormalities on physical examination. She had no underlying disease either. She underwent mitral and aortic valve replacement in addition to maze procedure for the atrial fibrillation without events. The ischemic time was 208 minutes and the total bypass time was 246 minutes, respectively. Immediately after surgery in the ICU, higher doses of inotropics and vasopressors were necessary to maintain her blood pressure (BP) (systolic BP around $80 \mathrm{mmHg}$ with dopamine $10 \mathrm{mcg} / \mathrm{kg} / \mathrm{min}$, dobutamine $10 \mathrm{mcg}$ / $\mathrm{kg} / \mathrm{min}$, norepinephrine $0.5 \mathrm{mcg} / \mathrm{kg} / \mathrm{min}$ and vasopressin 4 unit $/ \mathrm{h}$ ). Her cardiac index measured by a Swan-Ganz catheter ranged from $2.2 \mathrm{~L} / \mathrm{min} / \mathrm{m}^{2}$ to $2.4 \mathrm{~L} / \mathrm{min} / \mathrm{m}^{2}$. Hypoxia was noted as well $\left(\mathrm{PaO}_{2} 75 \mathrm{mmHg}\right.$ with $\mathrm{FiO}_{2} 1.0$ and PEEP 5

\footnotetext{
Received on March 30, 2016 Revised on June 10, 2016 Accepted on August 22, 2016

Correspondence to: Wan Ki Baek, Department of Thoracic and Cardiovascular Surgery, Inha University Hospital, 27 Inhang-ro, Jung-gu, Incheon 22332, Korea Tel: +82-32-890-2280, Fax: +82-32-890-3099, E-mail: wkbaek@inha.ac.kr

*No potential conflict of interest relevant to this article was reported.
} 
$\mathrm{cmH}_{2} \mathrm{O}$ ). $\mathrm{PaO}_{2}$ rose to $93.7 \mathrm{mmHg}$ with increasing positive end expiratory pressure (PEEP) to $7 \mathrm{cmH}_{2} \mathrm{O}$. We did not apply higher PEEP because of hemodynamic instability. Vasopressin and norepinephrine were tapered off gradually. On postoperative day 1 , she showed complete mental recovery. She opened eyes spontaneously, meeting gaze and obeyed command. Yet, her marginal hemodynamics and arterial blood gas profile (systolic BP $80-90 \mathrm{mmHg}$ with dopamine $10 \mathrm{mcg} / \mathrm{kg} / \mathrm{min}$ and dobutamine $10 \mathrm{mcg} /$ $\mathrm{kg} / \mathrm{min}, \mathrm{PaO}_{2}$ around $70 \mathrm{mmHg}$ with $\mathrm{FiO}_{2} 1.0$ and PEEP $4 \mathrm{cmH}_{2} \mathrm{O}$ ) required further ventilatory support. Fentanyl and vecuronium were given intermittently in a bolus of 50-100 mcg and 2-4 mg respectively until she was switched to the simultaneous intermittent mandatory ventilation (SIMV) mode on the second postoperative day. However, her respiratory status, which seemed to have improved slightly $\left(\mathrm{PaO}_{2} 76.9 \mathrm{mmHg}\right.$ with $\mathrm{FiO}_{2} 0.7$ and PEEP $7 \mathrm{mmHg}$ ), gradually deteriorated again as reflected by increasing pulmonary infiltrate and worsening $\mathrm{PaO}_{2}$. Superimposed recurrent atrial fibrillation and high fever $\left(38^{\circ} \mathrm{C}-39^{\circ} \mathrm{C}\right)$ worsened her condition. On postoperative day 4 , her respiratory rate rose up to $40 / \mathrm{min}$ and she was put back on the controlled mandatory ventilation mode again. Continuous infusion of fentanyl and vecuronium was initiated at the rate of $100 \mathrm{mcg} / \mathrm{hr}$ and $4 \mathrm{mg} / \mathrm{hr}$ respectively and she was paralyzed over the next 6 days. The intermittent interruption of the infusion was attempted in order to access mental status and neurologic deficit. Neuromuscular monitoring was not considered. Bispectral index monitoring was not considered either because fentanyl was administered in low dosage. Daily spontaneous awakening trial and breathing trial were largely postponed until the improvement of pulmonary infiltrate and blood gas profile was evident. Meanwhile, antibiotics were changed from vancomycin to meropenem plus amikacin empirically although no microorganism was documented from blood cultures. Hydrocortisone sodium succinate (solu-cortef $150 \mathrm{mg}$ a day) was administered intravenously for 3 days to overcome acute pulmonary dysfunction. Total serum bilirubin level had increased, peaking $15.4 \mathrm{mg} / \mathrm{dl}$ on postoperative day 7 , only to decline gradually thereafter. Serum aminotransferase did not elevate beyond $175 \mathrm{IU} / \mathrm{L}$. Blood urea nitrogen and serum creatinine were in the acceptable ranges.

Her pulmonary infiltrate had significantly improved on postoperative day 9 and she managed to be put on SIMV mode on postoperative day 10 . Thereafter, recovery was slow yet straightforward and she was barely extubated on postoperative day 14. After the extubation, though her blood gas profile was in an acceptable range, her respiratory pattern was shallow and labored. Sonographic assessment of the chest wall and diaphragm movement was not considered as the respiratory muscle incoordination was evident by physical assessment alone. She complained that she could not move at all. Limply waggling of her finger tips and toe tips was at her best. Her mental recovery was full and her senses were intact. No lateralizing sign was seen. She had no history of neuromuscular disorder. A neurological examination demonstrated symmetrical muscle weakness in both upper and lower extremities (Medical Research Council grade II) and decreased deep tendon reflexes. Normal results were observed on the mini-mental state examination, as well as on cranial nerve and sensory tests. No Babinski sign or ankle clonus was observed. Initally, we thought that it was due to the delayed effect of longstanding muscle relaxant administration. However, weakness of the extremities lasted longer than expected and she remained in bed for the next couple of weeks. She had to be intermittently catheterized because of voiding difficulty. Brain computerized tomography revealed no remarkable findings. Postoperative echocardiography on postoperative day 25 revealed well-functioning prosthetic valves and normal ventricular function.

Neurologic consultation suggested CINM as a cause and thus recommended electromyography (EMG) and nerve conduction velocity (NCV) study as well as acetylcholine receptor antibody test to rule out myasthenia gravis. Bedside physical therapy by professionals was encouraged following the initial studies.

Although the blood level of acetylcholine receptor antibody, creatine phosphokinase, and aldolase were in 
normal range, the result of EMG and NCV showed a pattern of diffuse axonal motor dominant polyneuropathy (Table 1). On EMG, fibrillation potentials and positive sharp waves, that reflects active denervation or myopathy, observed on plenty muscles with reduced recruitment pattern (Table 2). These electrophysiologic findings were consistent with of CINM.

She was transferred to the rehabilitation center and her condition and motor weakness gradually improved with time. On postoperative day 52, follow up NCV study revealed that compound motor action potentials markedly improved to a normal range and EMG study was normal (Table 1). She eventually recovered and discharged on postoperative day 64 , still in a state of mild weakness of her extremities, but leading a daily life without support.

Now she has been followed for 2 year, and is completely free of neurologic symptoms, and living a normal life.

\section{DISCUSSION}

The term CINM was first described by Bolton et al. [2]

Table 1. Series of nerve conduction studies

\begin{tabular}{|c|c|c|c|c|c|c|c|c|}
\hline \multirow{2}{*}{ Nerve / muscle } & \multicolumn{2}{|c|}{ Median / APB } & \multicolumn{2}{|c|}{ Ulnar / ADM } & \multicolumn{2}{|c|}{ Peroneal / EDB } & \multicolumn{2}{|c|}{ Tibial / AHB } \\
\hline & $\mathrm{DL}(\mathrm{ms})$ & Amp (mV) & $\mathrm{DL}(\mathrm{ms})$ & Amp (mV) & $\mathrm{DL}(\mathrm{ms})$ & Amp (mV) & $\mathrm{DL}(\mathrm{ms})$ & Amp (mV) \\
\hline \multicolumn{9}{|l|}{ Left } \\
\hline 22 Days after operation & 2.53 & $4.4^{\mathrm{a}}$ & 2.14 & $4.6^{\mathrm{a}}$ & 3.88 & $1.9^{\mathrm{a}}$ & 3.58 & 12.6 \\
\hline 53 Days after operation & 2.24 & 6.7 & 2.37 & 7.6 & 3.80 & $3.8^{\mathrm{a}}$ & 3.71 & 15.5 \\
\hline Difference & & +2.3 & & +3.0 & & +1.9 & & +2.9 \\
\hline \multicolumn{9}{|l|}{ Right } \\
\hline 22 Days after operation & 2.69 & $4.3^{\mathrm{a}}$ & 2.22 & $4.1^{\mathrm{a}}$ & 3.56 & $2.9^{\mathrm{a}}$ & 3.32 & 10.6 \\
\hline 53 Days after operation & 2.92 & 6.7 & 2.22 & 5.5 & 4.19 & 5.0 & 3.79 & 13.7 \\
\hline Difference & & +2.4 & & +1.4 & & +2.1 & & +3.1 \\
\hline
\end{tabular}

APB: abductor pollicis brevis; ADM: abductor digiti minimi; EDB: extensor digitorum brevis; AHB: abductor hallucis brevis; DL: distal latency; Amp: amplitude.

${ }^{a}$ Abnormal findings.

Table 2. Needle electromyography findings (22 days after operation)

\begin{tabular}{|c|c|c|c|c|c|}
\hline \multirow{2}{*}{ Muscle (left) } & \multirow{2}{*}{ Root } & \multirow{2}{*}{ Peripheral nerve } & \multicolumn{2}{|c|}{ Spontaneous activity } & \multirow{2}{*}{ Pattern of contraction } \\
\hline & & & Fibrillations & PSW & \\
\hline Paraspinal muscle (C5-C8, T1) & & & - & - & \\
\hline Biceps brachiia & C5-6 & MC nerve & $++^{\mathrm{a}}$ & $++^{\mathrm{a}}$ & Reduced recruitment ${ }^{\mathrm{a}}$ \\
\hline Deltoid $^{a}$ & C5-6 & Axillary nerve & $+^{\mathrm{a}}$ & $++^{\mathrm{a}}$ & Reduced recruitment ${ }^{\mathrm{a}}$ \\
\hline Triceps brachii & $\mathrm{C} 7,8$ & Radial nerve & - & - & Normal \\
\hline FDI & $\mathrm{C} 8-\mathrm{T} 1$ & Ulnar nerve & - & - & Normal \\
\hline APB & $\mathrm{C} 8-\mathrm{T1}$ & Median nerve & $++^{\mathrm{a}}$ & $++^{\mathrm{a}}$ & Reduced recruitment ${ }^{\mathrm{a}}$ \\
\hline Paraspinal muscles (L3-L5, S1) & & & - & - & \\
\hline Tibialis anterior & $\llcorner 4-5$ & Peroneal nerve & $++^{a}$ & $++^{\mathrm{a}}$ & Reduced recruitment ${ }^{\mathrm{a}}$ \\
\hline Gastrocnemius medialis & S1 & Tibial nerve & $++^{\mathrm{a}}$ & $++^{\mathrm{a}}$ & Reduced recruitment ${ }^{\mathrm{a}}$ \\
\hline AHB & S1 & Medial plantar nerve & $++^{\mathrm{a}}$ & $+^{\mathrm{a}}$ & Reduced recruitment ${ }^{\mathrm{a}}$ \\
\hline
\end{tabular}

PSW: positive sharp wave; MC: musculocutaneous; FDl: first dorsal interosseous; APB: abductor pollicis brevis; AHB: abductor hallucis brevis.

${ }^{a}$ Abnormal findings. 
in 1986 and has been reported sporadically thereafter in the setting of ICU on the way of managing a critical illness [3-5]. The disease primarily affects the motor and sensory axons and results in severe limb weakness rendering ventilator weaning extremely difficult. Characteristic clinical sign is flaccid and usually symmetric weakness. Deep tendon reflexes are usually reduced or absent. Sensory deficit is characterized by distal loss of sensitivity to stimuli. Facial muscles are usually not involved, although ophthalmoplegia is reported. The presentation of the disease is uniquely confined to the peripheral nervous system, yet the central nervous system involvement is not infrequently reported, as a form of diffuse encephalopathy in the early stage of the disease [6]. Ventilator weaning difficulty, usually encountered in ICU setting, is due to the involvement of the respiratory muscles. CINM could be differentiated into critical illness polyneuropathy and critical illness myopathy. However, they frequently cooccur, showing significant overlap in electrophysiological and histological findings. Therefore, they are usually taken as a same disease entity and called CIMN [1].

In addition to the typical clinical findings mentioned above, serum measurement of muscle necrosis parameters such as creatine kinase (CK), EMG and NCV studies, and muscle biopsy are commonly performed for the definite diagnosis. Serum CK levels are not informative in some cases since they do not rise at all or rise transiently if muscle necrosis is minimal or scattered. EMG and NCV studies are easy to perform bedside and highly recommended to rule out other causes of neuromuscular weakness in sedated and often uncooperative patients, enabling an earlier diagnosis. The reduction in amplitude of the nerve conduction potentials without reduction in velocity is the characteristic early sign of the disease. This sign often precedes clinical signs and other electrophysiologic signs such as fibrillation potentials and positive sharp waves. For the diagnosis, muscle biopsy remains the method of choice $[1,6,7]$. The procedure can be done easily performed at the bedside but not commonly performed as much due to its invasiveness. For the same reason, muscle biopsy was not performed in this case.
Considering that not a few cases are unrecognized, unattended or misinterpreted, the incidence rate is thought to be far more than reported. Latronico et al. [8] reported that about $60 \%$ of acute respiratory distress syndrome suffered from CINM. The disease occurred in $25 \%-33 \%$ on clinical grounds $[9,10]$ and up to $58 \%$ on electrophysiologic grounds $[11,12]$ of the unselected patients who had been on mechanical ventilation for minimum 4-7 days. It certainly has a negative impact on the clinical course of the patients. It may prolong the need for ventilatory support as the respiratory muscles are affected. Not infrequently, the duration of ventilatory support and weaning process was prolonged by 2 to 7 times [10,11]. ICU and hospital stays are prolonged as well. The recovery begins with progressive reinervation of motor and sensory nerves. Full recovery is expected in more than $50 \%$ of patients $[8,13]$. In severe cases, recovery may be delayed or may not occur at all [14].

Among many risk factors proposed by clinical trials, sepsis, systemic inflammatory response syndrome and multiorgan failure are regarded as consistent ones [1] although the exact roles in the pathophysiology are to be clarified. Hyperglycemia, also known as an independent risk factor, is thought to have a great potential impact in terms of prevention [15]. Disturbances of the microcirculation of the peripheral nerves and muscles are thought to be the crucial event in the pathogenesis. Cytokines increase microvascular permeability, resulting in endoneuronal edema, hypoxia and passage of neurotoxins. Severe energy deficit would induce primary axonal degeneration and further production of local cytokines [16]. No specific treatment had been proved to be effective and the only preventive measure was to control risk factors.

CINM in association with cardiac surgery has been largely unrecognized [17-20]. Alhan et al. [17] were the first to report a case of CINM in cardiac surgical unit after surgical repair of an acute aortic dissection. Recently, Thiele et al. [18] in their experience of seven CINM patients following cardiac surgery, reported that the development of CINM appeared to be not associated with a specific cardiac procedure nor prolonged bypass 
time. Additionally, the preoperative status of the patients did not associate with the development of the disease. Although the administration of corticosteroids, aminoglycosides and neuromuscular blocking agents are proposed as contributing factors to the occurrence of the disease, they also failed to identify a decisive risk factor among frequently mentioned ones such as sepsis, administration of corticosteroids, aminoglycosides, neuromuscular blocking agents and large dose of catecholamine, hypotensive shock and multiorgan failure. In fact, whether the associated clinical conditions imply a causal relationship or merely reflect severity of the disease remains to be solved. Judicious use of neuromuscular blockers with an appropriate neuromuscular monitoring device and tight control of the blood glucose level are encouraged to reduce the occurrence of the disease.

Further case collection and research addressing this complex pathophysiology of the disorder would enlighten the prevention and effective treatment of the disease.

\section{REFERENCES}

1. Hermans G, De Jonghe B, Bruyninckx F, Van den Berghe G. Clinical review: critical illness polyneuropathy and myopathy. Crit Care 2008;12:238.

2. Bolton CF, Laverty DA, Brown JD, Witt NJ, Hahn AF, Sibbald WJ. Critically ill polyneuropathy: electrophysiological studies and differentiation from Guillain-Barré syndrome. J Neurol Neurosurg Psychiatry 1986;49:563-73.

3. Zochodne DW, Bolton CF, Thompson RT, Driedger AA, Hahn AF, Gilbert JJ. Myopathy in critical illness. Muscle Nerve 1986;9:652.

4. Lacomis D, Zochodne DW, Bird SJ. Critical illness myopathy. Muscle Nerve 2000;23:1785-8.

5. Spitzer AR, Giancarlo T, Maher L, Awerbuch G, Bowles A. Neuromuscular causes of prolonged ventilator dependency. Muscle Nerve 1992;15:682-6.

6. Pandit L, Agrawal A. Neuromuscular disorders in critical illness. Clin Neurol Neurosurg 2006;108:621-7.
7. Lacomis D, Giuliani MJ, Van Cott A, Kramer DJ. Acute myopathy of intensive care: clinical, electromyographic, and pathological aspects. Ann Neurol 1996;40:645-54.

8. Latronico N, Shehu I, Seghelini E. Neuromuscular sequelae of critical illness. Curr Opin Crit Care 2005;11:381-90.

9. de Letter MA, Schmitz PI, Visser LH, Verheul FA, Schellens RL, Op de Coul DA, et al. Risk factors for the development of polyneuropathy and myopathy in critically ill patients. Crit Care Med 2001;29:2281-6.

10. De Jonghe B, Bastuji-Garin S, Sharshar T, Outin H, Brochard L. Does ICU-acquired paresis lengthen weaning from mechanical ventilation? Intensive Care Med 2004;30:1117-21.

11. Leijten FS, De Weerd AW, Poortvliet DC, De Ridder VA, Ulrich C, Harink-De Weerd JE. Critical illness polyneuropathy in multiple organ dysfunction syndrome and weaning from the ventilator. Intensive Care Med 1996;22:856-61.

12. Garnacho-Montero J, Amaya-Villar R, García-Garmendía JL, Madrazo-Osuna J, Ortiz-Leyba C. Effect of critical illness polyneuropathy on the withdrawal from mechanical ventilation and the length of stay in septic patients. Crit Care Med 2005;33:349-54.

13. de Sèze M, Petit H, Wiart L, Cardinaud JP, Gaujard E, Joseph PA, et al. Critical illness polyneuropathy: a 2-year follow-up study in 19 severe cases. Eur Neurol 2000;43:61-9.

14. Fletcher SN, Kennedy DD, Ghosh IR, Misra VP, Kiff K, Coakley JH, et al. Persistent neuromuscular and neurophysiologic abnormalities in long-term survivors of prolonged critical illness. Crit Care Med 2003;31:1012-6.

15. Van den Berghe G, Schoonheydt K, Becx P, Bruyninckx F, Wouters PJ. Insulin therapy protects the central and peripheral nervous system of intensive care patients. Neurology 2005;64:1348-53.

16. Bolton CF. Neuromuscular manifestations of critical illness. Muscle Nerve 2005;32:140-63.

17. Alhan HC, Cakalağaoğlu C, Hanci M, Toraman F, 
Idiz M, Kayacioğlu I, et al. Critical-illness polyneuropathy complicating cardiac operation. Ann Thorac Surg 1996;61:1237-9.

18. Thiele RI, Jakob H, Hund E, Genzwuerker H, Herold U, Schweiger P, et al. Critical illness polyneuropathy: a new iatrogenically induced syndrome after cardiac surgery? Eur J Cardiothorac Surg 1997;12:826-35.
19. Piper SN, Koetter KP, Triem JG, Guerter S, Schmidt C, Saggau W, et al. Critical illness polyneuropathy following cardiac surgery. Scand Cardiovasc J 1998;32:309-12.

20. Keaveney AM. Critical illness polyneuropathy in adults after cardiac surgery: a case study. Am J Crit Care 2004;13:421-4. 